\title{
ROAD SAFETY CAMPAIGNS TO REDUCE TRAFFIC ACCIDENTS FOR YOUNG ROAD USERS
}

\author{
Widodo Budi Dermawan and Dewi Nusraningrum \\ Universitas Mercu Buana Jakarta, Indonesia.
}

\begin{abstract}
Every year we lose many young road users in road traffic accidents. Based on traffic accident data issued by the Indonesian National Police in 2017, the number of casualties was highest in the age group 15-19, with 3,496 minor injuries, 400 seriously injured and 535 deaths. This condition is very alarming considering that student as the nation's next generation lose their future due to the accidents. This figure does not include other traffic violations, not having a driver license, not wearing a helmet, driving opposite the direction, those given ticket and verbal reprimand. To reduce traffic accident for young road user, road safety campaigns were organized in many schools in Jakarta. This activity aims to socialize the road safety program to increase road safety awareness among young road users/students including the dissemination of Law No. 22 of 2009 concerning Road Traffic and Transportation. Another purpose of this program is to accompany school administrators to set up a School Safe Zone (ZoSS), a location on particular roads in the school environment that are time-based speed zone to set the speed of the vehicle. The purpose of this paper is to promote the road safety campaigns strategies by considering various campaign tools.
\end{abstract}

Keywords: Road Safety, Campaign, Students, ZoSS

\section{Introduction}

Indonesia is the fourth most populous country in the world with more than 260 million people. The country's economic growth has given rise to increases in transportation demand and vehicle ownership. Road accidents in Indonesia have been arising on a growing trend in the previous decade. In April 2013, the President of the Republic of Indonesia issued Presidential Instruction (Inpres) Number 4 of 2013 concerning the 2011-2020 Road Safety Action Decade Program after the government set the Rencana Umum Nasional Keselamatan (RUNK) in May 2011 which in line with to the United Nations (UN) Program Decade of Action (DoA) for Road Safety 2011-2020 as stated in UN Resolution No. 64 / 255 of 2010.

The World Health Organization (WHO) has published in 2018 that road traffic injuries are currently the leading cause of death for children and young adults aged 5-29 years (WHO, 2018). According to data released by the Indonesian National Police in 2016, traffic accidents were recorded 105.374 cases that resulted in 25.859 people died, 22.939 people severe injury and 120.913 people minor injuries. It is known that road users in the 15-19 age group are the most vulnerable in Indonesia with 3,496 minor injuries, 400 seriously injured and 535 deaths in 2017. Figure 1 shows crash injury severity by age of road user.

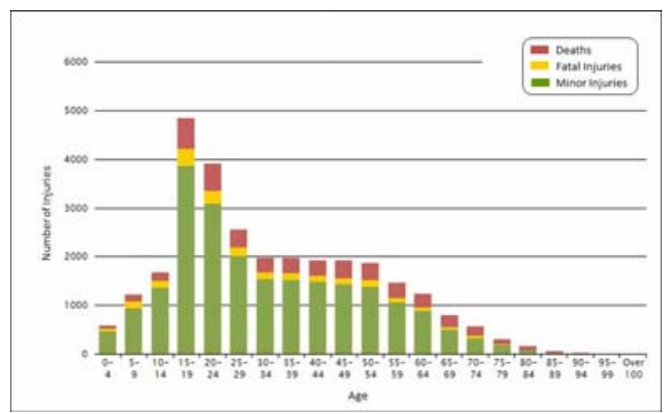

Figure 1. Crash Injury Severity by Age of Road User

From previous research, there are many factors that cause accidents, including human factors, vehicle factors and road environmental factors (Kartika, 2009). In fact accidents that take place on the roadway can be prevented by 
a better understanding of road users who prioritize safety. Referring to interviews with administrators of several Al Azhar Syifa Budi junior high schools in Jakarta, it was realized that the students' awareness and obeyance of road traffic rules were quite low. Therefore in order to increase awareness and knowledge about specific road safety problems, road safety campaigns are one of the approaches that school communities can use in their own neighborhood and can be adapted to a wide range of issues (Robyn, 2015). The purpose of this paper is to promote the road safety campaigns strategies by considering various campaign tools including the dissemination of Law No. 22 of 2009 concerning Road Traffic and Transportation.

\section{Background}

\section{Students' Road Safety Awareness}

Road safety awareness is a team responsibility of students, teacher, school authorities, and parents (Tamara, 2011). Understanding of the traffic rules of junior high school students is influenced by internal and external factors. Internal factors are traffic experiences given by parents and relatives at home, while external factors are interactions with other people such as friends in the school and in the neighborhood community. Some of the students' traffic common practices are identified as seen in Table 1.

Table 1. Students' Common Practice on the Roads

\begin{tabular}{|c|c|}
\hline Common Practice & Elucidation \\
\hline Play on the street & $\begin{array}{l}\text { Typically students in groups and play on the streets, in } \\
\text { particular after school hours. This not only can disrupt } \\
\text { the traffic flow of road around the school but also } \\
\text { potentially lead to traffic accidents. }\end{array}$ \\
\hline Crossing on the street & $\begin{array}{l}\text { Students tend to cross the road carelessly since not all } \\
\text { roads around the schools have road crossing facilities } \\
\text { such as pedestrian crossing or pedestrian bridges. This } \\
\text { situation can cause an accident. }\end{array}$ \\
\hline Riding a motorcycle & $\begin{array}{l}\text { Many students are permitted by parents to ride } \\
\text { motorbikes but do not have a driver license (SIM). This } \\
\text { is a violation of Law No. } 22 \text { of } 2009 \text { (UU Lalu lintas) } \\
\text { Article } 82 \text { paragraph } 2 \text { wherein children under the age of } \\
17 \text { cannot drive motorized vehicles because they do not } \\
\text { meet the age requirements for ownership of a SIM. In } \\
\text { addition, students often do not use helmets on short } \\
\text { distances trip. }\end{array}$ \\
\hline Driving habits & $\begin{array}{l}\text { Many students are permitted by their parents to go to } \\
\text { school by driving a car. Some of them do not have driver } \\
\text { license (SIM). Since schools have limited parking space, } \\
\text { some students parked the vehicle in the road sideways or } \\
\text { the street nearby that cause some distractions to other } \\
\text { road users and surroundings neighborhood. }\end{array}$ \\
\hline $\begin{array}{l}\text { Using conventional and online public } \\
\text { transportation }\end{array}$ & $\begin{array}{l}\text { Become a common thing that students have a habit of } \\
\text { not getting off at the bus stop. The reasons for this are } \\
\text { that there is no bus stop at the destination, the bus stop is } \\
\text { located far from the destination and the driver of public } \\
\text { transportation usually stops anywhere. }\end{array}$ \\
\hline
\end{tabular}




\section{Zona Selamat Sekolah (ZoSS)}

School Safety Zone / Zona Selamat Sekolah (ZoSS) is a program initiated by the Indonesian government through the Ministry of Transportation of the Directorate General of Land Transport which aims to protect school students from traffic accidents. School Safety Zone is a location on particular roads in the school environment that are time-based speed zone to set the speed of the vehicle (Dwi Putri, 2017) as seen in Figure2. The speed limit of ZoSS is generally $20-30 \mathrm{~km} / \mathrm{h}$. The determination of School Safety Zone (ZoSS) is based on the maximum number of lanes is 4 (four) lanes, no pedestrian bridges available, the school has the number of students above 50 students and has direct access to roads.

The School Safety Zone (ZoSS) is stated with road facilities such as road markings, traffic signs and road user safety device (Yogi, 2016). Based on the school's location criteria, ZoSS can be classified by single and plural ZoSS. Single ZoSS is a ZoSS designed for 1 (one) school in a location. Plural ZoSS is a ZoSS which is set for 2 (two) or more adjacent schools. Traffic management usually was guided by security officers or volunteers from the school which equipped with a reflective / fluorescent vest yellow and a stop sign board as seen in Figure 3 .

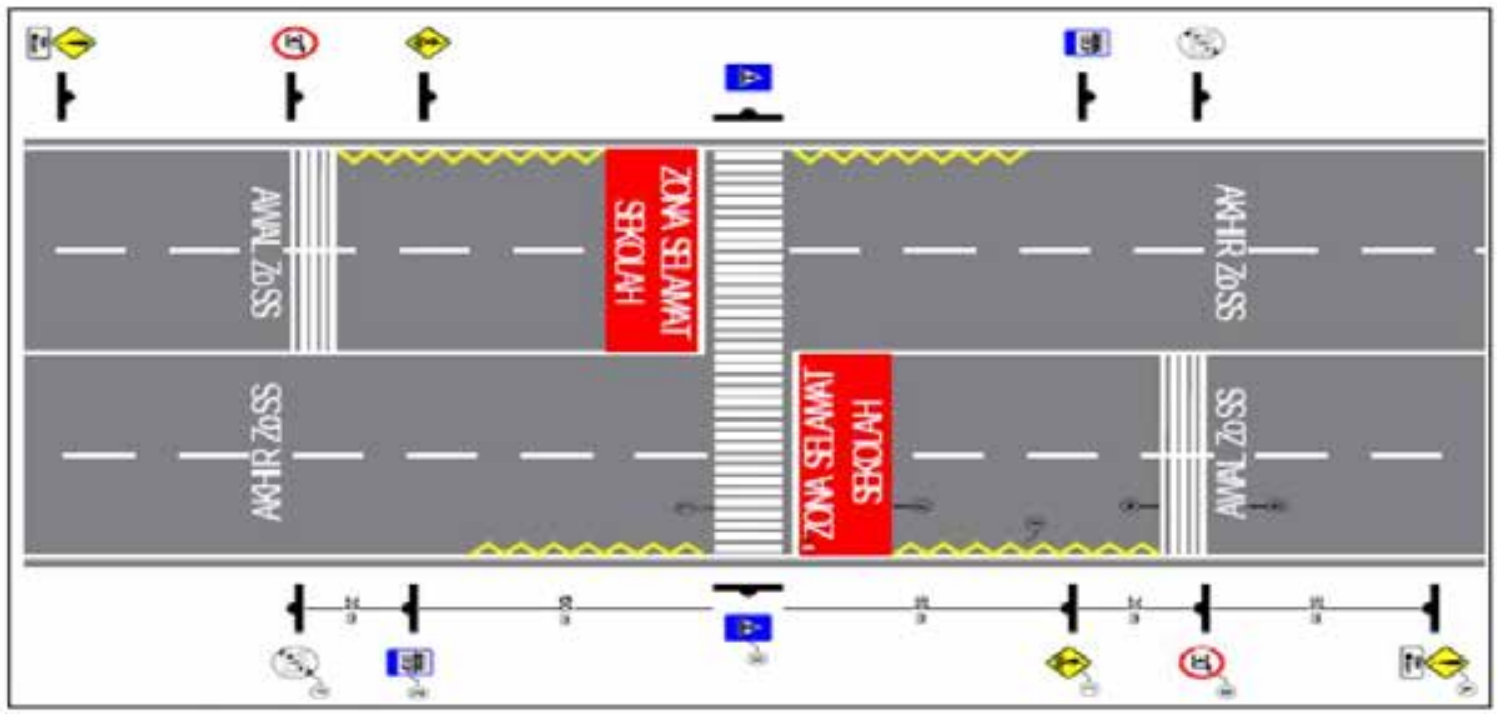

Source:SK 1304/AJ.403/DIPD/2014

Figure 2. School Safety Zone

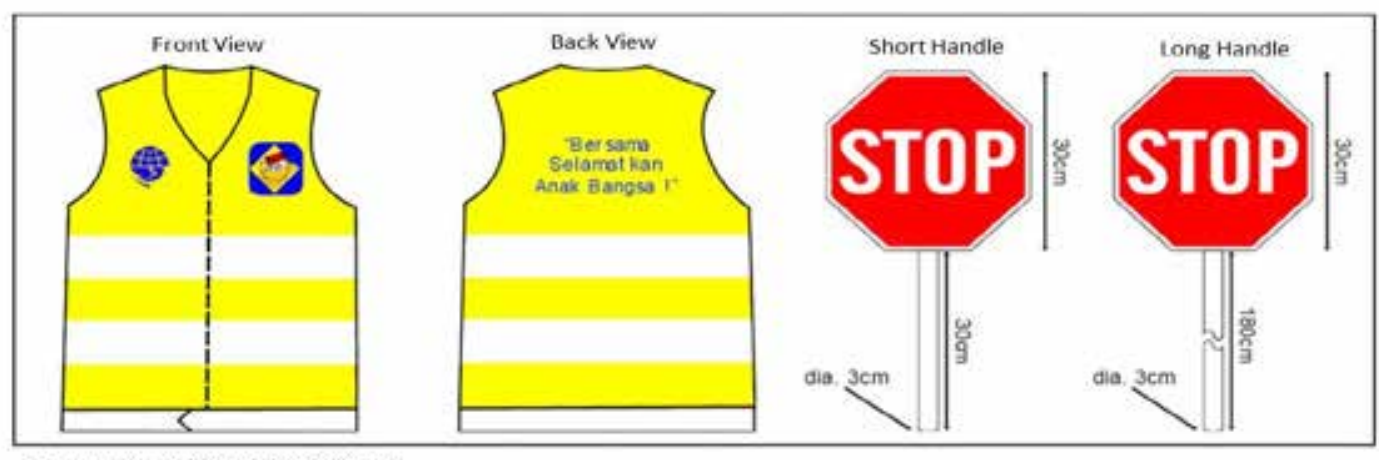

Source; SK 1304/AV,403/DIPD/2014

Figure 3. School Safety Zone's Equipment

Based on initial observation, there are many school administrators have not implemented ZoSS due to lack of information about the program. Then the road safety campaign will focus on increasing awareness of traffic rules among students and accompanying the school administrator to set up a School Safe Zone (ZoSS) 


\section{Road Safety Campaign Strategies}

\section{Campaign Messages}

The first step to start a road safety campaign is to get data and information to better understand the audience. Once a target audience has been identified and the necessary stakeholders established, the next step is to develop a campaign message. Developing an effective and attractive campaign message is crucial to capturing an audience's attention. There are four main approaches to campaign messages that are most often used in social campaigns (Robertson)

1. Positive messages. Previous study shows that audiences in general giving a better reaction to positive and constructive messages.

2. Fact-based messages. The use of research evidence to educate an audience about risks and consequences in a constructive way.

3. Fear-based appeals. This approach to road safety campaigns confronts people with visual images or associations of negative consequences of risky behaviours

4. Humor. The use of humor to deliver a key message is useful to engage the target audience and make them more receptive to the message and more open to suggestions.

\section{Campaign Activities}

In general road safety campaign activities can be carried out with 3 phases such as preparation phase, implementation phase and monitoring and evaluation phase as seen in Figure 4. During the preparation phase, a survey and test of students' understanding of traffic regulations are carried out. The results of this test will be used to prepare the next stage in the form of socializing road safety with the appropriate approach.

\section{Campaign Method}

The purpose of this project is to socialize the road safety program in the form of a Safer Journey to School program to both, school administrators and students. School administrators will be given assistance in the Safe Condition program, namely the proposed improvement of traffic safety facilities in the School Safe Zone (ZoSS) program.

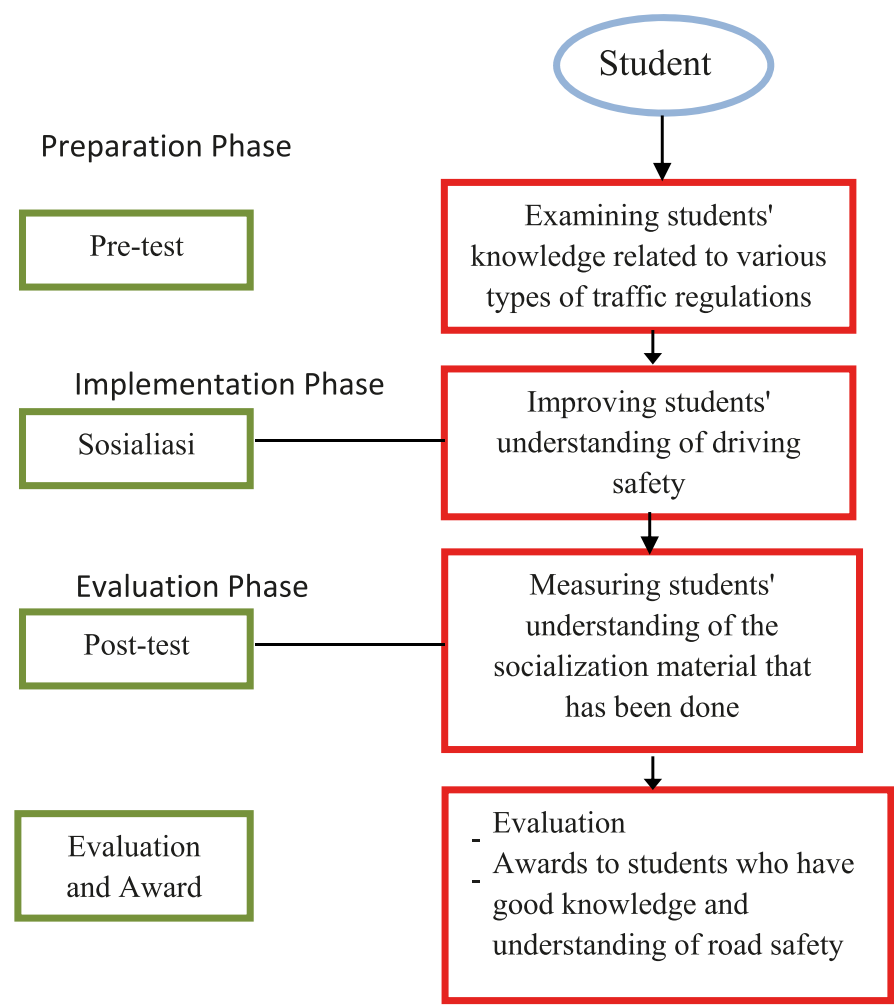

Figure 4. Campaign Phase 
Students will be invited in the form of Safe Action programs, to improving their knowledge and perceptions of road safety, culture, customs and ethics of traffic regulations including the dissemination of Law No. 22 of 2009 concerning Road Traffic and Transportation as seen in Figure 5.

Campaign methods can be conducted in several activities such as:

a. Seminar

This seminar is a socialization of road safety with the intention of knowing the extent to which students understand about road safety and traffic laws.

b. Interactive Dialogue

This interactive dialogue aims to provide a place for students who want to convey their aspirations regarding traffic rules. The dialogue will present members of the Jakarta Regional Police (Polda Metro)

c. Poster Competition

Road safety campaigns in the form of poster competitions are held to attract students to participate as road safety ambassadors. Posters will be assessed from road safety content and mass communication techniques. Selected posters will be proposed to be included in print mass media or on a national-level online media.

d. Visit to Traffic Management Center (TMC) Polda Metro Jaya

This visit is expected to add insight to selected student representatives about how road traffic is regulated. Students are expected to be able to understand the problems that exist in traffic management and solutions to overcome them.

e. ZoSS Assistance

One of the objectives of this program is to assist school operators in drafting and planning the School Safe Zone. Assistance begins with a discussion about the possibility that ZoSS can be adopted and what obstacles it has faced so far. Coordination with the transportation agencies and other relevant agencies is also needed.

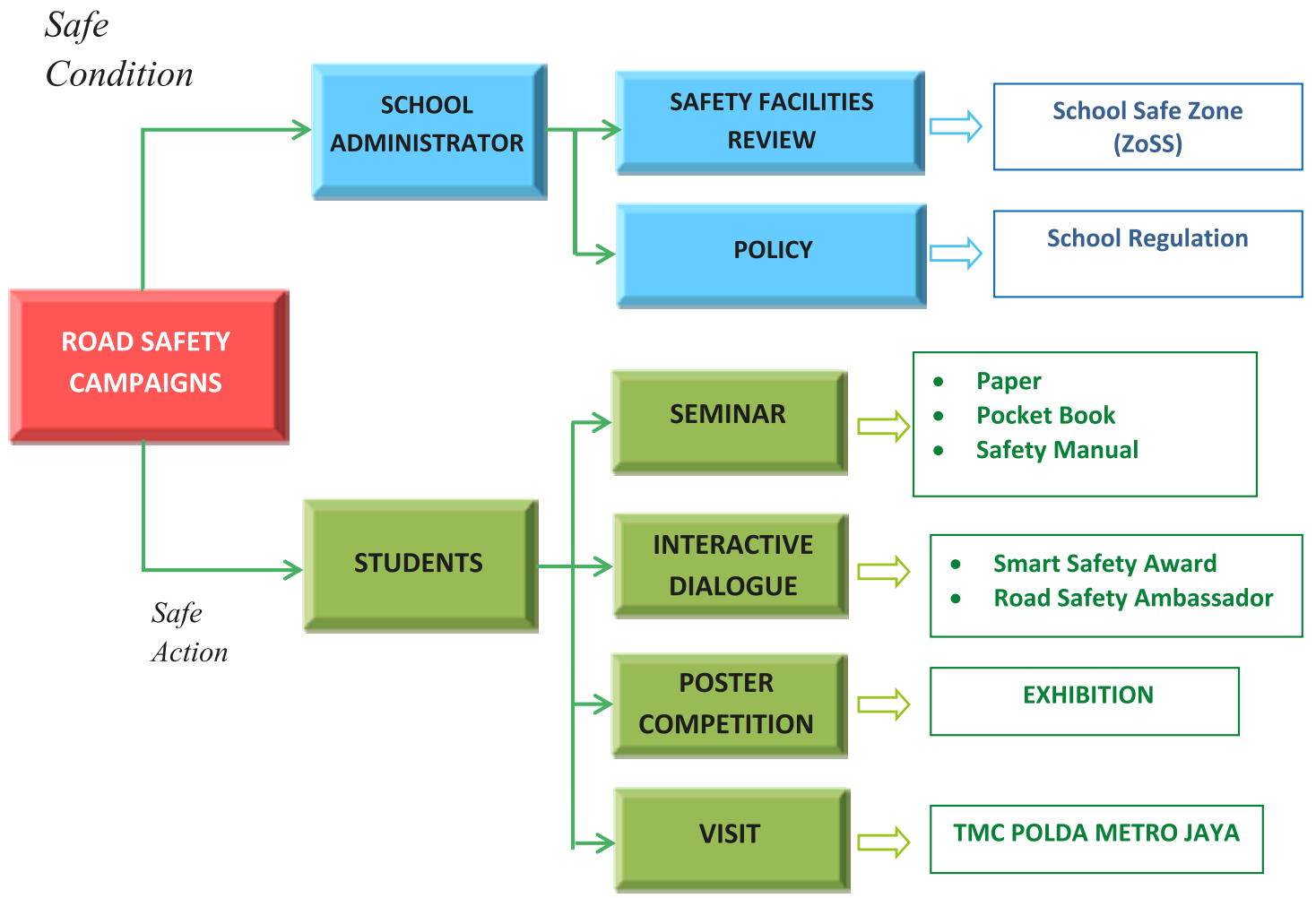

Figure 5. Campaign Methods 
Students will be invited in the form of Safe Action programs, to improving their knowledge and perceptions of road safety, culture, customs and ethics of traffic regulations including the dissemination of Law No. 22 of 2009 concerning Road Traffic and Transportation as seen in Figure 5.

Campaign methods can be conducted in several activities such as:

a. Seminar

This seminar is a socialization of road safety with the intention of knowing the extent to which students understand about road safety and traffic laws.

b. Interactive Dialogue

This interactive dialogue aims to provide a place for students who want to convey their aspirations regarding traffic rules. The dialogue will present members of the Jakarta Regional Police (Polda Metro)

c. Poster Competition

Road safety campaigns in the form of poster competitions are held to attract students to participate as road safety ambassadors. Posters will be assessed from road safety content and mass communication techniques. Selected posters will be proposed to be included in print mass media or on a national-level online media.

d. Visit to Traffic Management Center (TMC) Polda Metro Jaya

This visit is expected to add insight to selected student representatives about how road traffic is regulated. Students are expected to be able to understand the problems that exist in traffic management and solutions to overcome them.

e. ZoSS Assistance

One of the objectives of this program is to assist school operators in drafting and planning the School Safe Zone. Assistance begins with a discussion about the possibility that ZoSS can be adopted and what obstacles it has faced so far. Coordination with the transportation agencies and other relevant agencies is also needed.

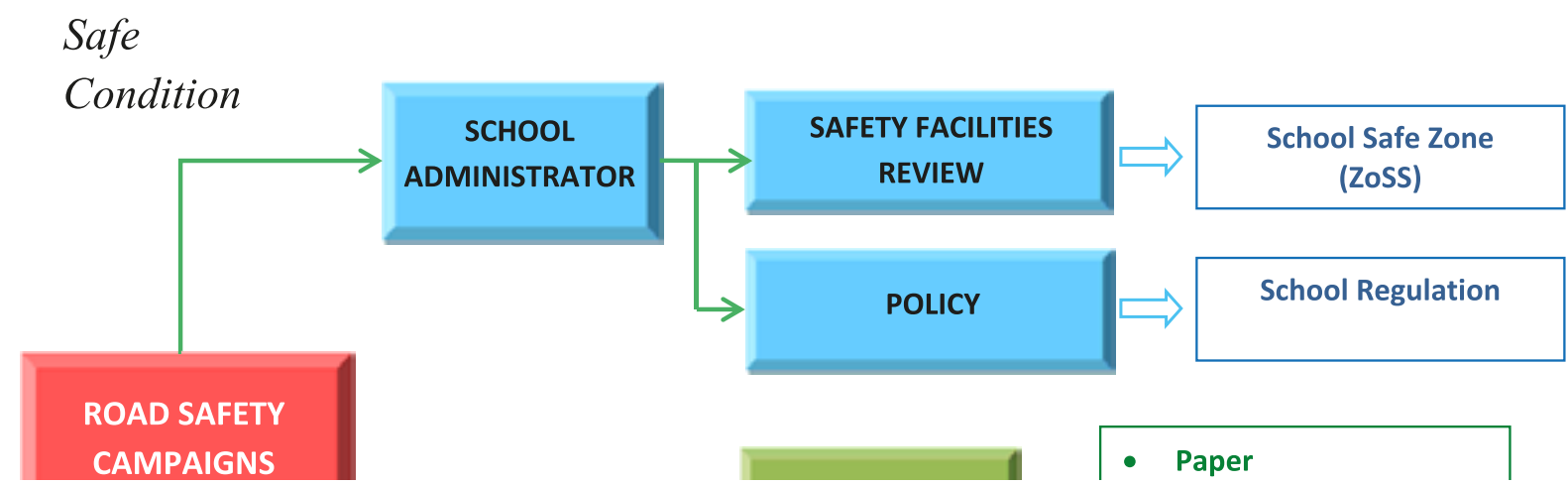

